\title{
Trabeculectomy versus Ahmed Glaucoma Valve implantation in neovascular glaucoma
}

This article was published in the following Dove Press journal:

Clinical Ophthalmology

28 February 201I

Number of times this article has been viewed

\author{
Christopher C Shen' \\ Sarwat Salim² \\ Haiming $\mathrm{Du}^{2}$ \\ Peter A Netland ${ }^{3}$ \\ 'Glaucoma Consultants Northwest, \\ Seattle, WA, USA; ${ }^{2}$ University of \\ Tennessee Health Science Center, \\ Memphis, TN, USA; ${ }^{3}$ University \\ of Virginia School of Medicine, \\ Charlottesville, VA, USA
}

Purpose: To compare surgical outcomes in neovascular glaucoma patients who underwent trabeculectomy with mitomycin $\mathrm{C}$ versus Ahmed Glaucoma Valve implantation.

Patients and methods: This was a retrospective comparative case series. We reviewed 40 eyes of 39 patients with underlying diagnosis of neovascular glaucoma, divided into two groups: Ahmed Glaucoma Valve $(\mathrm{N}=20)$ and trabeculectomy with mitomycin $\mathrm{C}(\mathrm{N}=20)$. Surgical success was defined as $6 \mathrm{~mm} \mathrm{Hg} \leq$ intraocular pressure $\leq 21 \mathrm{~mm} \mathrm{Hg}$, with or without the use of glaucoma medications, with no further glaucoma surgery, and light perception or better vision. Early postoperative hypotony was defined as intraocular pressure $<5 \mathrm{~mm} \mathrm{Hg}$ during the first postoperative week.

Results: The average follow-up was 31 months (range 6-87 months) for the Ahmed Glaucoma Valve group and 25 months (6-77 months) for the trabeculectomy group. Although the mean number of postoperative intraocular pressure-lowering medications was significantly higher in the trabeculectomy group compared with the Ahmed Glaucoma Valve group at 3 and 6 month time points, there was no statistically significant difference at any other time point. There was no statistically significant difference between both groups in postoperative visual acuity and intraocular pressure. Success was $70 \%$ and $65 \%$ at 1 year and $60 \%$ and $55 \%$ at 2 years after Ahmed Glaucoma Valve and trabeculectomy, respectively. Kaplan-Meier survival curve analysis showed no significant difference in success between the two groups $(P=0.815)$. Hyphema was the most common complication in both groups.

Conclusion: We found similar results after trabeculectomy with mitomycin $\mathrm{C}$ and Ahmed Glaucoma Valve implantation in eyes with neovascular glaucoma.

Keywords: glaucoma drainage implant, glaucoma filtering surgery, mitomycin C, neovascular glaucoma, intraocular pressure

\section{Introduction}

Neovascular glaucoma is a potentially devastating form of secondary glaucoma, which has a guarded visual prognosis. In the advanced stages of neovascular glaucoma, surgical management is often required to manage elevated intraocular pressure. The use of primary trabeculectomy with antifibrosis therapy and glaucoma drainage implant are two procedures often considered in managing patients who are refractory to medical therapy. Visual outcomes and surgical success for neovascular glaucoma patients treated with either procedure have been described. ${ }^{1-14}$ The aim of our study was to compare surgical outcomes after trabeculectomy with mitomycin $\mathrm{C}$ and the Ahmed Glaucoma Valve (New World Medical, Inc., Rancho Cucamonga, CA, USA) in patients with neovascular glaucoma.
Correspondence: Peter A Netland

Department of Ophthalmology,

University of Virginia School

of Medicine, P.O. Box 8007I5,

Charlottesville, VA 22908-07I5, USA

$\mathrm{Tel}+\mathrm{I} 4349821086$

Fax +l 4349245180

Email pnetland@virginia.edu 


\section{Material and methods}

This was a single-center, retrospective, comparative study. The study was approved by the Institutional Review Board, and informed consent was obtained before the surgical procedures. All procedures were performed by one surgeon from 1998 to 2007, and all eyes in the study had at least 6 months of postoperative follow-up. Consecutively treated eyes with neovascular glaucoma treated with trabeculectomy with mitomycin $\mathrm{C}$ were matched to consecutive eyes with neovascular glaucoma treated with the Ahmed Glaucoma Valve by age, race, and gender. In eyes treated with trabeculectomy, releasable sutures were not used; however, patients were treated with laser suture lysis if intraocular pressure was increased during the postoperative period. The timing of laser suture lysis and the intraoperative duration of exposure to mitomycin $\mathrm{C}$ (ranging from 2 minutes to 4 minutes) was according to surgeon preference. During the study period, fewer eyes with neovascular glaucoma were treated with trabeculectomy with mitomycin C, and unmatched eyes treated with the Ahmed Glaucoma Valve were not included in the analysis. Exclusion criteria included patient age $<18$ years, earlier cyclodestructive treatment, and earlier glaucoma drainage device implantation. Eyes in the trabeculectomy group with EX-PRESS ${ }^{\circledR}$ Glaucoma Filtration Device (Alcon, Inc., Fort Worth, TX) and eyes in both groups that received preoperative bevacizumab injections were not excluded.

Preoperative information included patient age, sex, race, glaucoma diagnosis, lens status, history of laser or surgical treatment for glaucoma, glaucoma medications, extent of angle closure, intraocular pressure measured by Goldmann applanation tonometry, and visual acuity expressed as the logarithm of the minimal angle of resolution ( $\log$ MAR). The primary outcome measures were visual acuity, number of postoperative glaucoma medications, intraocular pressure, and surgical success. Postoperative data regarding intraocular pressure, medications, visual acuity, and complications were obtained on days 1,7 , and 15, and months $1,3,6,12$, 15,18 , and 24. Results of the most recent examination were used for the analysis of intraocular pressure, visual acuity, and success at the last follow-up examination.

Criteria for success were defined before reviewing the data. Surgical success was defined as $6 \mathrm{~mm} \mathrm{Hg} \leq$ intraocular pressure $\leq 21 \mathrm{~mm} \mathrm{Hg}$, with or without glaucoma medications, without further glaucoma surgery including cyclophotocoagulation or complications that required removal of the Ahmed implant, and without loss of light perception. For failure due to elevated intraocular pressure, two consecutive visits with intraocular pressure $\geq 21 \mathrm{~mm} \mathrm{Hg}$ were required. Laser suture lysis and bleb needling to improve bleb function were not considered failure of the procedure. Potential postoperative complications for either procedure, including hyphema, choroidal effusions, tube erosion, early hypotony, bleb leak, strabismus, and suprachoroidal hemorrhage, were assessed. Bleb leak was considered a complication during the late postoperative period (more than 6 weeks after surgery), and early hypotony was defined as intraocular pressure $<5 \mathrm{~mm} \mathrm{Hg}$ during the first postoperative week.

The two groups were compared using the Mann-Whitney $U$ test for continuous variables, and the $\chi^{2}$ and Fisher exact test for categorical data. Success rates in both groups were compared using Kaplan-Meier life table analysis and the log-rank test. $P$ values of $<0.05$ were considered statistically significant.

\section{Results}

In this study, 40 eyes of 39 patients were treated with standard trabeculectomy with mitomycin C (20 eyes) or the Ahmed Glaucoma Valve (20 eyes). One patient had bilateral involvement of neovascular glaucoma and had separate eyes included in both treatment arms. Mean \pm standard deviation follow-up was $31.05 \pm 24.45$ months (range 6-87 months) for the trabeculectomy group and $25.00 \pm 19.74$ months (range 6-77 months) for the Ahmed Glaucoma Valve group $(P=0.477)$. The preoperative data for the two groups are shown in Table 1. There were no significant differences in sex, race, mean age, lens, status, previous glaucoma surgical treatment or panretinal photocoagulation, intraocular pressure, number of medications, etiology of neovascular glaucoma, extent of angle closure, or pre-existing primary open-angle glaucoma between the two groups. The intraoperative mitomycin $\mathrm{C}$ exposure time in the trabeculectomy group ranged from 2 minutes to 4 minutes at a concentration ranging from $0.2 \mathrm{mg} / \mathrm{mL}$ to $0.4 \mathrm{mg} / \mathrm{mL}$. One eye in the Ahmed Glaucoma Valve group and two eyes in the trabeculectomy group received an Avastin injection prior to glaucoma surgery (all three were ultimately classified as failures). Two patients in the trabeculectomy group had an EX-PRESS Glaucoma Filtration Device placed during the time of surgery (neither was ultimately classified as a failure).

Figure 1 shows the mean $\log M A R$ vision before and after trabeculectomy with mitomycin $\mathrm{C}$ and Ahmed Glaucoma Valve, with no significant differences between the two groups. Figure 2 shows the mean intraocular pressure before and after surgery in both the Ahmed Glaucoma 
Table I Preoperative characteristics of patients

\begin{tabular}{|c|c|c|c|}
\hline & $\begin{array}{l}\text { Drainage } \\
\text { implant } \\
(\mathbf{N}=\mathbf{2 0})\end{array}$ & $\begin{array}{l}\text { Trabeculectomy } \\
(\mathbf{N}=\mathbf{2 0})\end{array}$ & $P$ value \\
\hline \multicolumn{4}{|l|}{ Age (y) } \\
\hline Mean \pm SD & $54.0 \pm 15.6$ & $59.65 \pm 15.8$ & 0.342 \\
\hline Range & $27-88$ & $29-88$ & \\
\hline Gender (male:female) & $9: 11$ & $10: 10$ & 0.752 \\
\hline Race $(A A: C)$ & $16: 4$ & $14: 6$ & 0.465 \\
\hline Eye (OD:OS) & $12: 8$ & $11: 9$ & 0.749 \\
\hline Lens status & & & 0.197 \\
\hline Phakic & 10 & 12 & \\
\hline Pseudophakic & 3 & 0 & \\
\hline Aphakic & 7 & 8 & \\
\hline \multicolumn{4}{|l|}{ Preoperative Avastin } \\
\hline Yes & I & 2 & 0.549 \\
\hline No & 19 & 18 & \\
\hline \multicolumn{4}{|l|}{ Preoperative PRP } \\
\hline Yes & 18 & 17 & 0.632 \\
\hline No & 2 & 3 & \\
\hline \multicolumn{4}{|c|}{ Previous glaucoma surgery } \\
\hline Yes & $\mathrm{I}$ & 0 & 0.311 \\
\hline No & 19 & 20 & \\
\hline \multicolumn{4}{|c|}{ Primary open-angle glaucoma } \\
\hline Yes & 7 & 7 & 1.00 \\
\hline No & 13 & 13 & \\
\hline \multicolumn{4}{|c|}{ Etiology of neovascular glaucoma } \\
\hline PDR & 14 & 13 & \\
\hline CRVO & 3 & 4 & 0.981 \\
\hline CRAO & 2 & 2 & \\
\hline OIS & 1 & 1 & \\
\hline \multicolumn{4}{|l|}{ Gonioscopy } \\
\hline Open & 3 & 4 & \\
\hline $90^{\circ}$ closed & 0 & I & 0.446 \\
\hline $180^{\circ}$ closed & 4 & 2 & \\
\hline $270^{\circ}$ closed & 0 & 2 & \\
\hline $360^{\circ}$ closed & $\mathrm{II}$ & II & \\
\hline $\begin{array}{l}\text { Preoperative acuity } \\
(\text { logMAR, mean } \pm \text { SD) }\end{array}$ & $2.11 \pm 0.62$ & $1.88 \pm 0.65$ & 0.314 \\
\hline $\begin{array}{l}\text { Preoperative } \\
\text { intraocular pressure } \\
(\mathrm{mm} \mathrm{Hg} \text {, mean } \pm \mathrm{SD})\end{array}$ & $47.7 \pm 10.2$ & $47.8 \pm 11.3$ & 0.926 \\
\hline $\begin{array}{l}\text { Preoperative } \\
\text { medications } \\
(\text { mean } \pm S D)\end{array}$ & $3.4 \pm 1.2$ & $3.6 \pm 1.1$ & 0.603 \\
\hline
\end{tabular}

Abbreviations: AA, African American; C, Caucasian; CRAO, central retinal artery occlusion; CRVO, central retinal vein occlusion; logMAR, logarithm of the minimal angle of resolution; OD, right eye; OIS, ocular ischemic syndrome; OS, left eye; PDR, proliferative diabetic retinopathy; PRP, panretinal photocoagulation; $\mathrm{SD}$, standard deviation.

Valve and trabeculectomy groups. In both groups, the mean postoperative intraocular pressures at all follow-up time points were lower than the mean preoperative intraocular pressure. The mean intraocular pressure did not differ statistically between the two groups at any postoperative time point. Figure 3 shows the mean number of pre- and postoperative

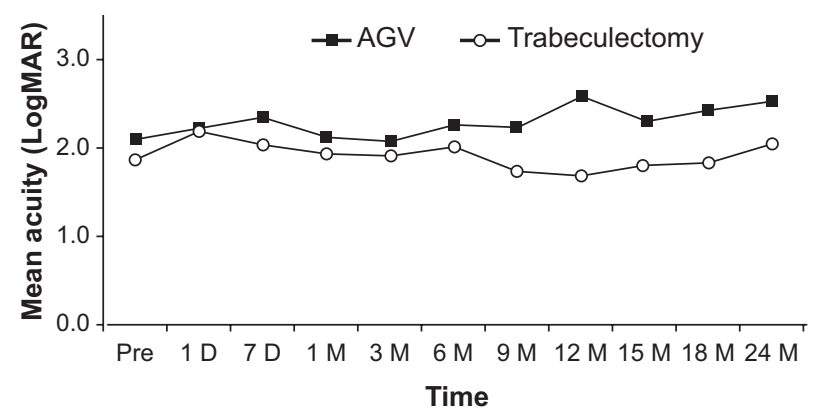

Figure I Mean logarithm of the minimal angle of resolution (logMAR) vision before and after trabeculectomy with mitomycin C and Ahmed Glaucoma Valve (AGV). There were no significant differences between the two groups. Abbreviations: D, day(s); M, month(s); Pre, preoperative.

glaucoma medications in both groups. The trabeculectomy group required a statistically significantly greater number of postoperative medications at months 3 and 6; however, there was no significant difference between both groups in all other time points.

Kaplan-Meier survival curves following trabeculectomy and the Ahmed Glaucoma Valve are shown in Figure 4. There were no treatment failures in either group within the first 3 months of postoperative follow-up. The success rates were $90 \%$ and $85 \%$ at 6 months, $85 \%$ and $80 \%$ at 9 months, $70 \%$ and $65 \%$ at 12 months, $70 \%$ and $60 \%$ at 15 months, $60 \%$ and $60 \%$ at 18 months, and $60 \%$ and $55 \%$ at 24 months in the Ahmed Glaucoma Valve and trabeculectomy groups, respectively. The numbers of patients were 20 and 20 at 6 months, 16 and 20 after 1 year, and 14 and 19 at 24 months after Ahmed Glaucoma Valve and trabeculectomy, respectively. The difference between the survival curves was not statistically significant $(P=0.815)$.

Comparisons at the last follow-up examination between the Ahmed Glaucoma Valve and trabeculectomy groups are shown in Table 2. There was no statistically significant difference between groups in comparisons of mean follow-up interval,

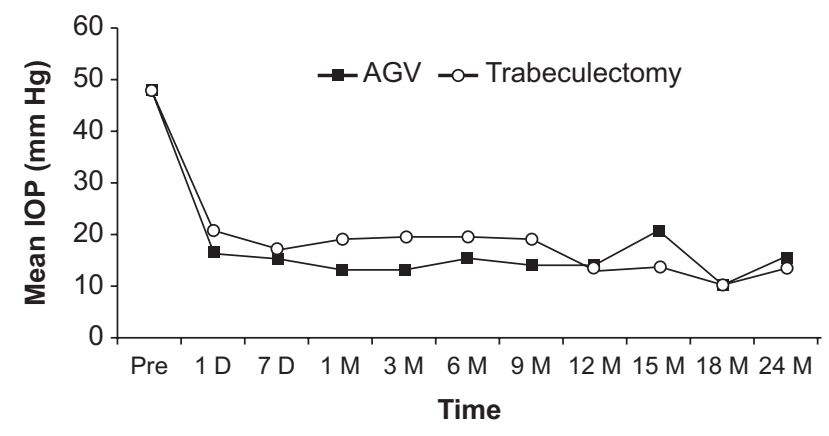

Figure 2 Mean intraocular pressure (IOP) before and after surgery in both the Ahmed Glaucoma Valve (AGV) and trabeculectomy groups. The mean IOP did not differ statistically between the two groups at any postoperative time point.

Abbreviations: D, day(s); M, month(s); Pre, preoperative. 


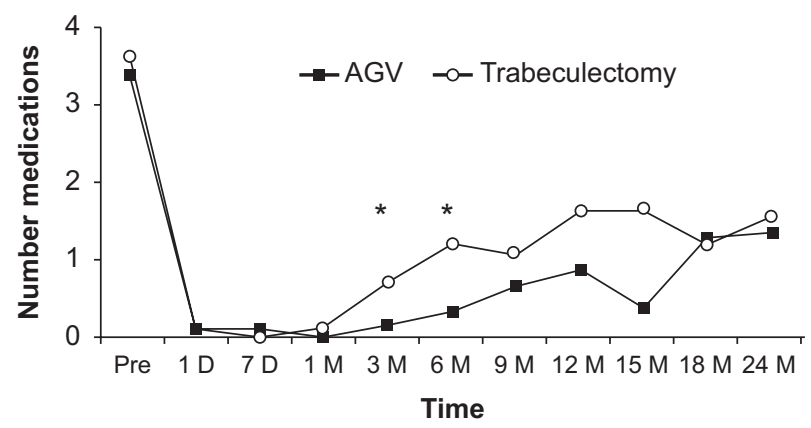

Figure 3 Mean number of pre- and postoperative glaucoma medications after Ahmed Glaucoma Valve (AGV) and trabeculectomy. The trabeculectomy group required a statistically significantly greater number of glaucoma medications at months 3 and 6 (asterisks); however, there was no significant difference between both groups in all other time points.

Abbreviations: D, day(s); M, month(s); Pre, preoperative.

intraocular pressure, postoperative medications, and overall rate of surgical success. The success rate was $60 \%$ for the Ahmed Glaucoma Valve group and 55\% for the trabeculectomy group $(P=0.474)$. In the Ahmed Glaucoma Valve group, a total of eight eyes were classified as failures: four eyes had deterioration of visual acuity to no light perception, two eyes developed total retinal detachments, one eye was enucleated secondary to no light perception and pain, and one eye had a final intraocular pressure $<5 \mathrm{~mm} \mathrm{Hg}$ at the final follow-up examination. In the trabeculectomy group, a total of nine eyes were classified as failures: three eyes had deterioration of visual acuity to no light perception, one eye required Ahmed Glaucoma Valve implantation for control of intraocular pressure, one eye was treated with a Baerveldt Glaucoma Implant (Abbott Medical Optics, Santa Ana, CA) for intraocular pressure control, one eye required cyclophotocoagulation for intraocular pressure control, two eyes had intraocular pressure $>21 \mathrm{~mm} \mathrm{Hg}$ at final examination, and one eye had intraocular pressure $<5 \mathrm{~mm}$ $\mathrm{Hg}$ at final examination.

Postoperative complications in both groups are summarized in Table 3. Hyphema was the most common complication,

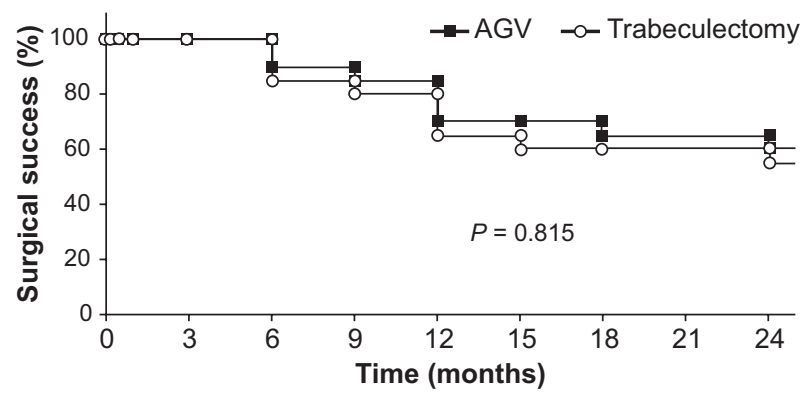

Figure 4 Kaplan-Meier survival curves following trabeculectomy and Ahmed Glaucoma Valve (AGV). The success rates were $70 \%$ and $65 \%$ at 12 months, and $60 \%$ and $55 \%$ at 24 months in the AGV and trabeculectomy groups, respectively. The difference between the survival curves was not statistically significant $(P=0.8 \mid 5)$.
Table 2 Last follow-up examination

\begin{tabular}{|c|c|c|c|}
\hline & $\begin{array}{l}\text { Drainage } \\
\text { implant } \\
(\mathbf{N}=\mathbf{2 0})\end{array}$ & $\begin{array}{l}\text { Trabeculectomy } \\
(\mathbf{N}=20)\end{array}$ & $P$ value \\
\hline $\begin{array}{l}\text { Follow-up interval } \\
\text { (months, mean } \pm \mathrm{SD} \text { ) }\end{array}$ & $31.1 \pm 24.5$ & $25.0 \pm 19.7$ & 0.477 \\
\hline $\begin{array}{l}\text { Visual acuity } \\
(\log M A R, \text { mean } \pm S D)\end{array}$ & $2.6 \pm 0.3$ & $2.0 \pm 0.8$ & $0.01 \mathrm{I}^{\mathrm{a}}$ \\
\hline $\begin{array}{l}\text { Postoperative } \\
\text { intraocular pressure } \\
(\mathrm{mm} \mathrm{Hg} \text {, mean } \pm \mathrm{SD})\end{array}$ & $13.7 \pm 13.1$ & $16.5 \pm 10.9$ & 0.289 \\
\hline $\begin{array}{l}\text { Postoperative medications } \\
(\text { mean } \pm S D)\end{array}$ & $1.0 \pm 1.5$ & $1.8 \pm 1.7$ & 0.150 \\
\hline \multicolumn{4}{|l|}{ Surgical outcome } \\
\hline Success & $12(60 \%)$ & II (55\%) & 0.474 \\
\hline Failure & $8(40 \%)$ & $9(45 \%)$ & \\
\hline
\end{tabular}

Note: ${ }^{p}<0.05$.

Abbreviations: logMAR, logarithm of the minimal angle of resolution; SD, standard deviation.

occurring in seven eyes (35\%) in the Ahmed Glaucoma Valve group and eight eyes (40\%) in the trabeculectomy group. One eye $(5 \%)$ had choroidal effusion during the early postoperative period in the Ahmed Glaucoma Valve group, and one eye (5\%) developed a suprachoroidal hemorrhage in the trabeculectomy group. Early postoperative hypotony and late wound leak occurred in the trabeculectomy group in two eyes $(10 \%)$ and one eye (5\%), respectively. There was no occurrence of flat anterior chamber, hypotony maculopathy, or endophthalmitis in either group.

\section{Discussion}

Patients with neovascular glaucoma that is refractory to medical and laser therapy are often managed with glaucoma drainage implants or trabeculectomy with antimetabolites. ${ }^{13,14}$ Glaucoma drainage implants may be recommended as a primary surgical procedure in patients with neovascular glaucoma, especially in eyes with severe inflammation

Table 3 Complications

\begin{tabular}{lll}
\hline & $\begin{array}{l}\text { Drainage implant } \\
(\mathbf{N}=\mathbf{2 0})\end{array}$ & $\begin{array}{l}\text { Trabeculectomy } \\
(\mathbf{N}=\mathbf{2 0})\end{array}$ \\
\hline $\begin{array}{l}\text { Hyphema } \\
\text { Choroidal effusion }\end{array}$ & 7 & 8 \\
$\begin{array}{l}\text { Suprachoroidal } \\
\text { hemorrhage }\end{array}$ & 0 & 0 \\
$\begin{array}{l}\text { Early hypotony } \\
\text { Late wound leak }\end{array}$ & 0 & $\mathrm{I}$ \\
$\begin{array}{l}\text { Endophthalmitis } \\
\text { Total number of }\end{array}$ & 0 & 2 \\
complications $^{\mathrm{b}}$ & 8 & $\mathrm{I}$ \\
\hline
\end{tabular}

Notes: aEarly hypotony defined as intraocular pressure $<5 \mathrm{~mm} \mathrm{Hg}$ during the first postoperative week; ${ }^{\mathrm{D}} \mathrm{No}$ significant differences by comparison of proportions (z) test. 
at presentation. ${ }^{15,16}$ However, trabeculectomy with antifibrosis drugs such as mitomycin $\mathrm{C}$ may be an appropriate procedure for neovascular glaucoma. ${ }^{17}$ In this study, we found similar surgical outcomes in patients with neovascular glaucoma treated with the Ahmed Glaucoma Valve or trabeculectomy with mitomycin $\mathrm{C}$.

In a previous study of trabeculectomy with mitomycin C in 24 eyes with neovascular glaucoma, Hyung and $\mathrm{Kim}^{18}$ found a surgical success rate of $71 \%$ at 1 month and $29 \%$ at 1 year after surgery. In 15 eyes with neovascular glaucoma treated with trabeculectomy with mitomycin C, Mandal et al ${ }^{11}$ had a higher success rate of $66.7 \%$ at 1 year after surgery, which is comparable with the results in our trabeculectomy group (65\%). After Ahmed Glaucoma Valve implantation in 38 eyes with neovascular glaucoma, Yalvac et $\mathrm{al}^{12}$ had a surgical success rate of $63.3 \%$ at 1 year, which was comparable with the success rate at 1 year after Ahmed Glaucoma Valve implantation in our study (70\%). Im et al ${ }^{10}$ directly compared treatment with both Ahmed Glaucoma Valve and trabeculectomy with mitomycin $\mathrm{C}$, with complete success defined as intraocular pressure $<21 \mathrm{~mm} \mathrm{Hg}$ without medication, and qualified success as $<21 \mathrm{~mm} \mathrm{Hg}$ with medication. At 1 year after trabeculectomy and Ahmed Glaucoma Valve implantation, complete success was $47.8 \%$ and $42.3 \%$ and qualified success was $30.4 \%$ and $46.2 \%$, respectively. Our success rates may have been higher due to differences in inclusion and exclusion criteria or other variables. Despite having lower surgical success rates at 1 year after surgery, there was no statistical difference between both groups, consistent with our findings.

In our study, despite control of intraocular pressure after the procedure, three patients in the trabeculectomy group and six patients in the Ahmed Glaucoma Valve group lost light perception vision. This has been described previously in neovascular glaucoma patients and has been attributed to possible progression of the underlying disease., ${ }^{74,19-21}$ Use of antivascular endothelial growth factor (anti-VEGF) drugs may improve outcomes after glaucoma surgery in eyes with neovascular glaucoma. ${ }^{22,23}$ In eyes with neovascular glaucoma, Lupinacci et $\mathrm{al}^{24}$ found improved visual outcomes and reduced need for glaucoma surgery after intravitreal bevacizumab treatment, although eyes with closed angles required surgery despite anti-VEGF treatment. Although only a single case in the Ahmed Glaucoma Valve group and two cases in the trabeculectomy group received an intravitreal bevacizumab injection in the preoperative period, all three cases were ultimately classified as failures based on the criteria in this study, possibly due to advanced disease at the time of presentation. Although the EX-PRESS implantation has similar long-term success compared with trabeculectomy in other types of glaucoma, ${ }^{25}$ the number of patients with the EX-PRESS implant (two) was too low to detect any influence on success in neovascular glaucoma or potential bias of the study.

The nonrandomized retrospective design of this study has potential sources of bias. To minimize any bias, patients in each group were matched based on age, sex, and race. No major differences were observed in the preoperative characteristics of the patients, including the preoperative vision and the extent of angle closure. Nonetheless, patients treated with cyclophotocoagulation or other drainage implants were excluded from the study, and surgeon preference determined whether the patient was treated with the Ahmed Glaucoma Valve or trabeculectomy. Thus, the possibility of investigator bias exists in this study, including the possibility that patients were selected for either procedure based on criteria not measured in this study. Also, the sample size was small, introducing the possibility of a type II (false negative) statistical error. Our study did not evaluate the surgical outcomes after prior vitrectomy, which has been identified as a prognostic factor for surgical failure for trabeculectomy ${ }^{26}$ but not for the Ahmed Glaucoma Valve. ${ }^{27}$ Our assessment of the number of complications after trabeculectomy was likely low because we did not include early bleb leaks and bleb needling as complications. An advantage of this study was the follow-up period being, on average, over 2 years, which is relatively long compared with other studies of neovascular glaucoma patients, due to increased mortality and poor compliance with follow-up due to other systemic comorbidities. ${ }^{28,29}$

\section{Conclusion}

We found similar intraocular pressure reduction and surgical success after use of Ahmed Glaucoma Valve and trabeculectomy with mitomycin $\mathrm{C}$ in the treatment of neovascular glaucoma. Hyphema was the most common postoperative complication encountered in both groups, and other complications were relatively uncommon. Although success rates decline over time after either procedure, both Ahmed Glaucoma Valve and trabeculectomy with mitomycin $\mathrm{C}$ may be useful in the treatment of neovascular glaucoma that is refractory to medical and laser therapy.

\section{Acknowledgement}

Presented in part at the Association for Research in Vision and Ophthalmology Annual Meeting, Fort Lauderdale, Florida, 
USA, on May 3, 2009 and the American Glaucoma Society Annual Meeting, Naples, Florida, USA, on March 4, 2010.

\section{Disclosure}

The authors report no conflicts of interest in this work.

\section{References}

1. Tsai JC, Feuer WJ, Parrish RK II, Grajewski AL. 5-Fluorouracil filtering surgery and neovascular glaucoma. Long-term follow-up of the original pilot study. Ophthalmology. 1995;102:887-892.

2. Katz GJ, Higginbotham EJ, Lichter PR, et al. Mitomycin C versus 5 -fluorouracil in high-risk glaucoma filtering surgery. Extended follow-up. Ophthalmology. 1995;102:1263-1269.

3. Kiuchi Y, Nakae K, Saito Y, et al. Pars plana vitrectormy and panretinal photocoagulation combined with trabeculectomy for successful treatment of neovascular glaucoma. Graefes Arch Clin Exp Ophthalmol. 2006;244:1627-1632.

4. Elgin U, Berker N, Batman A, et al. Trabeculectomy with mitomycin C combined with direct cauterization of peripheral iris in the management of neovascular glaucoma. J Glaucoma. 2006;15:466-470.

5. Sisto D, Vetrugno M, Trabucco T, et al. The role of antimetabolites in filtration surgery for neovascular glaucoma: intermediate-term follow-up. Acta Ophthalmol Scand. 2007;85:267-271.

6. Al-Obeidan SA, Osman EA, Al-Amro SA, et al. Full preoperative panretinal photocoagulation improves the outcome of trabeculectomy with mitomycin C for neovascular glaucoma. Eur J Ophthalmol. 2008; 18:758-764.

7. Netland PA. The Ahmed Glaucoma Valve in neovascular glaucoma. Trans Am Ophthalmol Soc. 2009;107:325-342.

8. Wilson MR, Mendis U, Paliwal A, Haynatzka V. Long-term follow-up of primary glaucoma surgery with Ahmed Glaucoma Valve implant versus trabeculectomy. Am J Ophthalmol. 2003;136:464-470.

9. Wilson MR, Mendis U, Smith SD, Paliwal A. Ahmed Glaucoma Valve implant vs trabeculectomy in the surgical treatment of glaucoma: a randomized clinical trial. Am J Ophthalmol. 2000;130:267-273.

10. Im YW, Lym HS, Park CK, Moon JI. Comparison of mitomycin C trabeculectomy and Ahmed Valve Implant surgery for neovascular glaucoma. J Korean Ophthalmol Soc. 2004 45:1515-1521.

11. Mandal AK, Majji AB, Mandal SP, et al. Mitomycin-C-augmented trabeculectomy for neovascular glaucoma. A preliminary report. Indian J Ophthalmol. 2002;50:287-293.

12. Yalvac IS, Eksioglu U, Satana B, Duman S. Long-term results of Ahmed Glaucoma Valve and Molteno implant in neovascular glaucoma. Eye. 2007;21:65-70.

13. Tsai JC, Feuer WJ, Parrish RK 2nd, Grajewski AL. 5-Fluorouracil filtering surgery and neovascular glaucoma: long-term follow-up of the original pilot study. Ophthalmology. 1995;102:887-892.
14. Sidoti PA, Dunphy TR, Baerveldt G, et al. Experience with the Baerveldt Glaucoma Implant in treating neovascular glaucoma. Ophthalmology. 1995;102:1107-1118.

15. Borisuth NS, Phillips B, Krupin T. The risk profile of glaucoma filtration surgery. Curr Opin Ophthalmol. 1999;10:112-116.

16. Sivak-Callcott JA, O'Day DM, Gass DM, et al. Evidence-based recommendations for the diagnosis and treatment of neovascular glaucoma. Ophthalmology. 2001;108:1767-1778.

17. Kiuchi Y, Sugimoto R, Nakae K, et al. Trabeculectomy with mitomycin $\mathrm{C}$ for treatment of neovascular glaucoma in diabetic patients. Ophthalmologica. 2006;220:383-388.

18. Hyung SM, Kim SK. Mid-term effects of trabeculectomy with mitomycin C in neovascular glaucoma patients. Korean J Ophthalmol. 2001;15:98-106.

19. Parrish R, Herschler J. Eyes with end-stage neovascular glaucoma. Natural history following successful modified filtering operation. Arch Ophthalmol. 1983;101:745-746.

20. Mermoud A, Salmon JF, Alexander P, et al. Molteno tube implantation for neovascular glaucoma. Long-term results and factors influencing the outcome. Ophthalmology. 1993;100:897-902.

21. Every SG, Molteno ACB, Bevin TH, Herbison P. Long-term results of Molteno implant insertion in cases of neovascular glaucoma. Arch Ophthalmol. 2006;124:355-360.

22. Wakabayashi T, Oshima Y, Sakaguchi H, et al. Intravitreal bevacizumab to treat iris neovascularization and neovascular glaucoma secondary to ischemic retinal diseases in 41 consecutive cases. Ophthalmology. 2008;115:1571-1580.

23. Ehlers JP, Spirn MJ, Lam A, et al. Combination intravitreal bevacizumab/ panretinal photocoagulation versus panretinal photocoagulation alone in the treatment of neovascular glaucoma. Retina. 2008;28:696-702.

24. Lupinacci APC, Calzada JI, Rafieetery M, et al. Clinical outcomes of patients with anterior segment neovascularization treated with or without intraocular bevacizumab. Adv Ther. 2009;26:208-216.

25. Maris PJG Jr, Ishida K, Netland PA. Comparison of trabeculectomy with EX-PRESS miniature glaucoma device implanted under scleral flap. J Glaucoma. 2007;16:14-19.

26. Takihara Y, Inatani M, Fukushima M, et al. Trabeculectomy with mitomycin $\mathrm{C}$ for neovascular glaucoma: prognostic factors for surgical failure. Am J Ophthalmol. 2009;147:912-918.

27. Park UC, Park KH, Kim DM, Yu HG. Ahmed Glaucoma Valve implantation for neovascular glacuoma after vitrectomy for proliferative diabetic retinopathy. J Glaucoma. Sep 16, 2010. [Epub ahead of print].

28. Gartner S, Henkind P. Neovascularization of the iris (rubeosis iridis). Surv Ophthalmol. 1978;22:291-312.

29. Blanc JP, Molteno ACB, Fuller JR, et al. Life expectancy of patients with neovascular glaucoma drained by Molteno implants. Clin Experiment Ophthalmol. 2004;32:360-363.
Clinical Ophthalmology

\section{Publish your work in this journal}

Clinical Ophthalmology is an international, peer-reviewed journal covering all subspecialties within ophthalmology. Key topics include: Optometry; Visual science; Pharmacology and drug therapy in eye diseases; Basic Sciences; Primary and Secondary eye care; Patient Safety and Quality of Care Improvements. This journal is indexed on Submit your manuscript here: http://www.dovepress.com/clinical-ophthalmology-journal

\section{Dovepress}

PubMed Central and CAS, and is the official journal of The Society of Clinical Ophthalmology (SCO). The manuscript management system is completely online and includes a very quick and fair peer-review system, which is all easy to use. Visit http://www.dovepress.com/ testimonials.php to read real quotes from published authors. 